\title{
Fibronectin suppression in head and neck cancers, inflammatory tissues and the molecular mechanisms potentially involved
}

\author{
ULF HENNING BEIER $^{1}$, CLAUDIA HOLTMEIER ${ }^{2}$, JAN BERND WEISE ${ }^{3}$ and TIBOR GÖRÖGH ${ }^{3}$ \\ ${ }^{1}$ Department of Pediatrics, University of Illinois at Chicago, Chicago, Illinois, USA; ${ }^{2}$ Department of Dermatology, \\ and ${ }^{3}$ Division of Molecular Oncology at the Department of Otorhinolaryngology, Head and Neck Surgery, \\ University of Schleswig-Holstein, Campus Kiel, Kiel, Germany
}

Received August 25, 2006; Accepted October 23, 2006

\begin{abstract}
Epithelial cellular fibronectin is frequently repressed after malignant transformation in a variety of cancers. This change has been associated with a loss of contact inhibition. To determine if these findings are unique to malignant processes and to identify mechanisms responsible for fibronectin suppression, we investigated fibronectin expression patterns in 46 head and neck carcinomas, 16 samples of adenoid tissue, and 10 benign mucosal biopsies. We report fibronectin suppression in $78 \%$ of the head and neck cancer samples, occurring most prominently within tumor cells, as opposed to the adjacent stroma which exhibited abundant fibronectin. Interestingly, fibronectin was also strongly repressed in chronically inflamed adenoid samples. We showed that fibronectin suppression is mediated by different mechanisms in both benign as well as malignant scenarios: In adenoids, macrophages and T-cells were visualized throughout epithelium that has lost its tight cellular array, allowing leukocyte passage. We have shown that tumor necrosis factor- $\alpha$ secreted by macrophages is capable of inducing epithelial derangement via activator protein-1 and nuclear factor- $\kappa \mathrm{B}$ mediated fibronectin suppression. In head and neck carcinomas, we identified human papilloma virus early protein-2 as a fibronectin transcription inhibitor. We conclude that epithelial fibronectin suppression may not be a hallmark of malignancy, because it can concur with benign processes that involve leukocyte migration. Furthermore, our data suggest that the pattern of fibronectin suppression within the tumor structure largely depends on the cancer cell-stroma relation, which could explain previous conflicting reports on
\end{abstract}

Correspondence to: Dr Tibor Görögh, Division of Molecular Oncology at the Department of Otorhinolaryngology, Head and Neck Surgery, University of Schleswig-Holstein, Campus Kiel, Arnold-Heller-Str. 14, D-24105 Kiel, Germany

E-mail: gorogh@hno.uni-kiel.de

Key words: fibronectin suppression, head and neck squamous cell carcinomas, leukocyte migration, tumor necrosis factor- $\alpha$, human papilloma virus early protein-2 its repression or overexpression along with malignant transformation. In addition, our data support an involvement of human papilloma virus as a mechanism of carcinogenesis mediated via a loss of fibronectin gene expression.

\section{Introduction}

Head and neck squamous cell carcinomas (HNSCC) are characterized by an aggressive growth pattern and early metastatic spread which contribute to their high morbidity and mortality $(1,2)$. The molecular genetic background facilitating this behavior has been studied extensively, and several genes have been described to be involved in HNSCC carcinogenesis (3-7). Fibronectin (FN) has been reported to be down-regulated in HNSCC, and it was suggested that its suppression mediates a loss of contact inhibition due to reduced cellular adhesion, which promotes mitosis and cellular spreading (8).

FN is an adhesive glycoprotein of approximately 220$250 \mathrm{kDa}$. There are two principal types of FN, including plasmatic and cellular surface bound forms, which are generated from the same gene transcript by alternate splicing $(9,10)$. Cellular surface $\mathrm{FN}$ is located in fibrillar arrays on the surface of many types of cells, including fibroblasts, astrocytes, epithelial and endothelial cells, and others $(11,12)$. Cellular surface FN functions as a cell-cell and cell-substrate binding molecule, facilitating cellular adhesion, attachment to extra cellular matrix macromolecules, and contact inhibition, among others $(13,14)$. A major source of interest in FN derived from the finding that the expression of cellular surface FN is repressed after malignant transformation (15-19). However, in addition to the data connecting FN suppression to malignancy, Akiyama et al reported increased FN expression within tumorassociated fibroblasts actually enhancing tumor cell motility, cancer spread, and metastasis formation, which led to a controversial discussion on the role of $\mathrm{FN}$ in carcinogenesis (20).

In this study, we examined the expression of cellular surface FN in 46 HNSCC tissue samples (Table I) and compared them to 16 chronically inflamed adenoids as well as 10 benign mucosa samples, both on the transcriptional and on the translational level. Our objective was to assess the expression pattern of FN in HNSCC, and to investigate whether the phenomenon of FN repression is exclusively limited to malignant tissues. 
Table I. Head and neck carcinoma samples.

\begin{tabular}{|c|c|c|c|c|c|}
\hline \multirow[t]{2}{*}{ Kind of tumor } & \multirow[t]{2}{*}{$(\mathrm{N})$} & \multicolumn{4}{|c|}{ Relative FN-mRNA expression ${ }^{a}$} \\
\hline & & Absent & Decreased & Equivalent & Increased \\
\hline Carcinoma of the floor of the mouth & 2 & 2 & - & - & - \\
\hline Laryngeal carcinoma & 11 & 10 & - & 1 & - \\
\hline Carcinoma of the root of the tongue & 3 & 2 & - & 1 & - \\
\hline Hypopharyngeal carcinoma & 2 & 2 & - & - & - \\
\hline Metastasis ${ }^{\mathrm{b}}$ & 3 & 3 & - & - & - \\
\hline Tonsillar carcinoma & 23 & 5 & 11 & 3 & 4 \\
\hline Parotoid carcinoma & 1 & 1 & - & - & - \\
\hline Carcinoma of the paranasal sinus & 1 & - & - & 1 & - \\
\hline Total $[\mathrm{n}(\%)]$ & $46(100)$ & $25(54.3)$ & $11(23.9)$ & $6(13.0)$ & $4(8.7)$ \\
\hline
\end{tabular}

\section{Materials and methods}

Tissue samples. A total of 72 tissue samples, including 46 HNSCC (Table I), 16 adenoid tissues and 10 benign mucosa biopsies were obtained during surgery after receiving written patient consent, in accordance with the ethics commission of the University of Schleswig-Holstein, Campus Kiel, based on the 1975 Helsinki Declaration (revised 1983). The histologic diagnoses of primary HNSCC, inflammatory adenoids, and normal mucosa were established by certified pathologists of the University of Schleswig-Holstein, Campus Kiel. Immediately after obtaining tissue samples, they were frozen in liquid nitrogen, crumbled in a mortar, and stored at $-80^{\circ} \mathrm{C}$ for further processing.

Cell culture. Cell cultures derived from well-characterized University of Turku Squamous Cell Carcinoma (UTSCC)-19A laryngeal SCC cell lines were grown in minimum essential medium with Earle's salts and L-glutamine without the addition of non-essential amino acids and sodium bicarbonate, but in the presence of $20 \mathrm{mM} \mathrm{N}-2$-Hydroxyethylpiperazine-N'-2ethanesulfonic acid and $10 \%(\mathrm{v} / \mathrm{v})$ fetal calf serum (Biochrome, Berlin, Germany), in $5 \% \mathrm{CO}_{2}$ at $37^{\circ} \mathrm{C}$ in a humidified atmosphere (21). Primary keratinocyte cultures, derived from adjacent normal mucosa of the larynx, were cultivated in serum-free medium (Gibco, Eggenstein, Germany), supplemented with $50 \mu \mathrm{g} / \mathrm{ml}$ bovine pituitary extract and $1.5 \mathrm{ng} / \mathrm{ml}$ epidermal growth factor in the presence of $100 \mathrm{U} / \mathrm{ml}$ penicillin/ streptomycin (22). Bacterial contamination of the cultures was excluded after culture of the medium at $37^{\circ} \mathrm{C}$ with and without cells.

Isolation of total RNA. Total RNA isolation from frozen tissue samples was achieved with the RNeasy kit (Qiagen, Hilden, Germany) following the manufacturer's instructions. After determination of the RNA content using the UVICON-931
UV-spectralphotometer (Kontron, Hamburg, Germany), samples of total RNA were adjusted to $2.0 \mu \mathrm{g}$ for the upcoming first-strand cDNA synthesis.

Northern hybridization. A 790-bp probe capable of annealing to FN-mRNA was designed for Northern hybridization using the sense primer 5'-CTC AAC AGA CAA CCA AAC T-3', and the antisense primer 5'-CCT TGT CAT CCT TGA CAG TG-3'. The probe was labeled by chemiluminescence (Boehringer, Mannheim, Germany). After labeling the probe, $20 \mu \mathrm{g}$ of heat-denaturated RNA derived from the HNSCC samples, adenoid tissues, and keratinocytes was employed for Northern blotting. Following electrophoretic separation in a $1.5 \%$ agarose gel with $0.01 \%$ ethidium bromide staining for visualizing the $28 \mathrm{~S}$ and $18 \mathrm{~S}$ rRNA bands, the gels were blotted via capillary transfer onto a positively charged nylon membrane (Boehringer) at room temperature overnight. The transferred RNA was subsequently immobilized using UV radiation. The membranes were hybridized at $50^{\circ} \mathrm{C}$ for $14 \mathrm{~h}$ in Easy Hyb solution (Boehringer) containing $25 \mathrm{ng} / \mathrm{ml}$ of the DNA probe indicated above. After the membranes were washed twice in $0.3 \mathrm{mM} \mathrm{NaCl}, 30 \mathrm{mM}$ sodium citrate $(\mathrm{pH} 7.0)$ containing $0.1 \%(\mathrm{w} / \mathrm{v})$ sodium dodecyl sulfate (SDS) at room temperature for $15 \mathrm{~min}$ each, they were then washed in $70 \mu \mathrm{M}$ $\mathrm{NaCl}, 7.0 \mathrm{mM}$ sodium citrate $(\mathrm{pH} 7.0)$ containing $0.1 \%$ SDS at $68^{\circ} \mathrm{C}$ for $15 \mathrm{~min}$. The membranes were prepared for chemiluminescence detection by adding disodium 3-(-4methoxyspiro 1,2-dioxetane-3, 2'-(chloro)tricyclodecan-4-yl) phenyl phosphate (Boehringer) according to the manufacturer's instructions. A glutaraldehyde-3-phosphatedehydrogenase (G3PDH) probe was used to standardize comparisons of the FN expression levels. Finally, the blots were exposed to an $\mathrm{X}$-ray film (20 $\mathrm{min}$ ) using an intensifier screen.

Densitometry. Northern hybridization gels were scanned and quantified using Herolab E.A.S.Y. Win32 software (Herolab, 
Wiesloch, Germany). The intensity of the FN bands was divided by the corresponding G3PDH signals from the same sample.

ELISA. To quantify FN production, the homogenates of the five laryngeal and mucosal biopsies were compared using the FN enzyme immunoassay kit (Boehringer). Measurements were made by absorbance at $492 \mathrm{~nm}$, using the EIA plate reader MR5000 (Dynatech, Chantilly, VA). ELISA procedures were performed in triplicate.

Immunohistochemistry. The tissue samples derived from the same groups mentioned above were placed in $10 \%$ neutral buffered formalin immediately after they were obtained and were allowed to fix for 24-48 h. After fixation, the samples were dehydrated and embedded in methylmethacrylate plastic. After polymerization, the samples were cut on a plane rightangled to the tissue surface. Longitudinal sections of $4 \mu \mathrm{m}$ were cut with a rotary saw microtome and transferred onto a microscopic slide. For immunohistochemical examination, sections of tissue were deparaffinized in four cycles of Xylol for $10 \mathrm{~min}$ each. The samples were rehydrated in aqua dest for $10 \mathrm{~min}$. Antigen retrieval was accomplished by washing the samples with Tris-buffered saline (TBS) solution for $5 \mathrm{~min}$. Endogenous peroxidase was blocked for 30 min with $1 \%$ hydrogen peroxide in methanol. Non-specific immunoglobulin binding was blocked by incubation of the slides for $10 \mathrm{~min}$ with a $3 \%$ goat serum in TBS for 20 min prior to application of the primary antibodies, i.e. anti-FN (R\&D Systems, Wiesbaden, Germany) and Ki-M1P (23). The samples were incubated with the primary antibodies for $60 \mathrm{~min}$. Subsequently, the samples were washed twice with TBS and Tween for $3 \mathrm{~min}$ each. A biotinylated rabbit antibody was applied to the slides for $30 \mathrm{~min}$, and the samples were washed as above. A labeled peroxidase complex system (ABC-Vectorstatin, Dako, Hamburg, Germany) was used to visualize all immune reactions. Sections were counterstained with Mayer's hematoxylin. For negative controls, the primary antibodies were replaced with homologous non-immune sera. The slides were evaluated in cooperation with the Pathology department of the University of Schleswig-Holstein, Campus Kiel.

Immunocytochemistry. Cell cultures were grown on sterile slides up until cellular confluence was achieved, washed with PBS solution, and fixed in absolute ethanol for $10 \mathrm{~min}$. After fixation, the samples were processed by a similar protocol as described above for the immunohistochemistry.

Electrophoretic mobility shift assay. UTSCC-19A and normal epithelial cells were washed in PBS, centrifuged at $800 \mathrm{rpm}$ and the pellets were resuspended in sucrose buffer containing $30 \mathrm{mM}$ sucrose, $0.5 \mathrm{ml} 1 \mathrm{M}$ Tris ( $\mathrm{pH} \mathrm{8.0),} 150 \mu 11 \mathrm{M} \mathrm{CaCl}_{2}$, $100 \mu 11 \mathrm{M} \mathrm{MgOAc}, 10 \mu 10.5 \mathrm{mM}$ phenyl-methyl-sulfonylfluoride, $1 \mathrm{mM}$ dithiothreitol, $0.5 \%$ (v/v) Nonidet-NP40 (Fluka Chemie, Buchs, Switzerland). After centrifugation at $500 \mathrm{rpm}$ for $5 \mathrm{~min}$, the cell pellets were washed in the same buffer without Nonidet-NP40, centrifuged again and resuspended in $100 \mu 1$ low salt buffer containing $1 \mathrm{mM}$ HEPES, $0.075 \mathrm{mM}$ $\mathrm{MgCl}_{2}, 1 \mathrm{mM} \mathrm{KCl}, 0.01 \mathrm{mM}$ EDTA (pH 8.0), 32\% glycerole, $0.5 \mathrm{mM}$ dithiothreitol, and $0.5 \mathrm{mM}$ phenyl-methyl-sulfonyl-
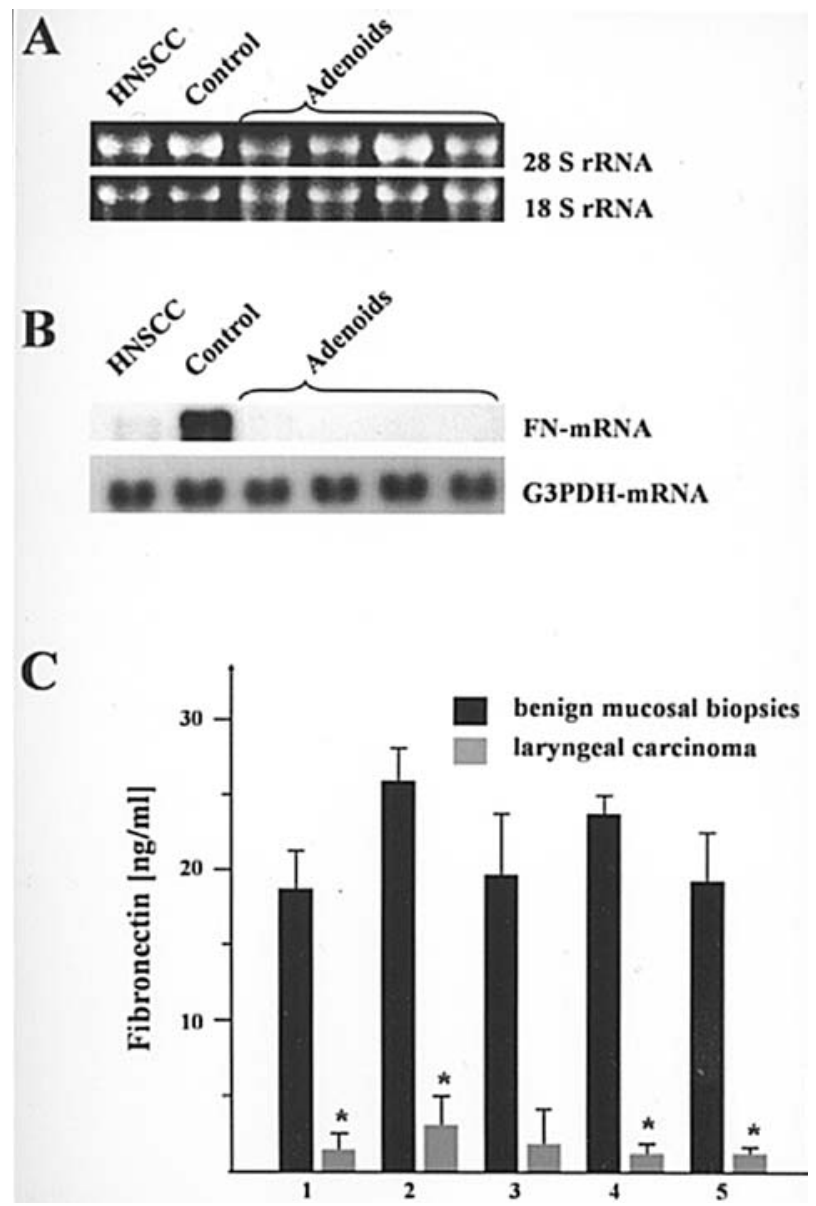

Figure 1. Fibronectin expression in head and neck carcinomas and adenoids, fibronectin production in laryngeal carcinomas compared to benign control. (A) Quality assessment of the RNA isolation. (B) Upper Panel, Northern hybridization with fibronectin-cDNA probe. Lower panel, Northern hybridization with G3PDH-cDNA probe. Total RNA is present in sufficient quality and quantity. Fibronectin is repressed in the carcinoma sample compared to benign mucosa control. Fibronectin is prominently repressed in the adenoid samples. (C) ELISA of five native laryngeal carcinoma samples compared to benign epithelial phenotypes. The bars indicate standard deviations of four single measurements per culture. ${ }^{*} \mathrm{p}<0.05$. G3PDH, glutaraldehyde-3-phosphatedehydrogenase; FN, fibronectin; S, Svedberg.

fluoride. Subsequently, nuclear extracts were treated with $40 \mathrm{mM}$ of protease inhibitor (Roche Molecular Biochemicals, Mannheim, Germany) and the protein concentrations were measured using the method of Bradford (24). The EMSA nuclear extracts of $1 \mu \mathrm{g}$ each were incubated in a $10-\mu 1$ reaction mixture consisting of $0.5 \mu \mathrm{g}$ poly(dI-dC), $2 \mu \mathrm{l}$ binding buffer $50 \mathrm{mM}$ Tris ( $\mathrm{pH} \mathrm{8.0),} 750 \mathrm{mM} \mathrm{KCl}, 2.5 \mathrm{mM}$ EDTA, 0.5\% Triton-X $100(\mathrm{v} / \mathrm{v}), 62 \%$ glycerol (v/v), $1 \mathrm{mM}$ dithiothreitol and $\left[\alpha_{-}{ }^{32} \mathrm{P}\right]-\mathrm{dATP}-$ labeled oligonucleotides. The sequences of oligonucleotides used in this assay were: oligonucleotide 1 $(-40$ to +1$), 5$ '-CGG GAG GGC CGT CCC ATA TAA GCC CGG CTC CCG CGC TCC GA-3'; oligonucleotide 2 (-71 to -41), 5'-TCC TCC CCC GCG CCC CGG GCC TCC AGA GGG G-3'); oligonucleotide 3 (-119 to -72 ), 5'-GGG CGG GCG GGT GGG GTG GGG CGG GGC GGG GAC AGC CCG GCG GGT CTC-3'; oligonucleotide 4 (-153 to -120$)$, 5'-GGC CAA TCG GGC GCG GTC GGC TGC GGC GGC CGG C-3'; oligonucleotide 5 (-187 to -154), 5'-ACC CAC AGT CCC CCG TGA CGT CAC CCG GAG CCC G-3'; 

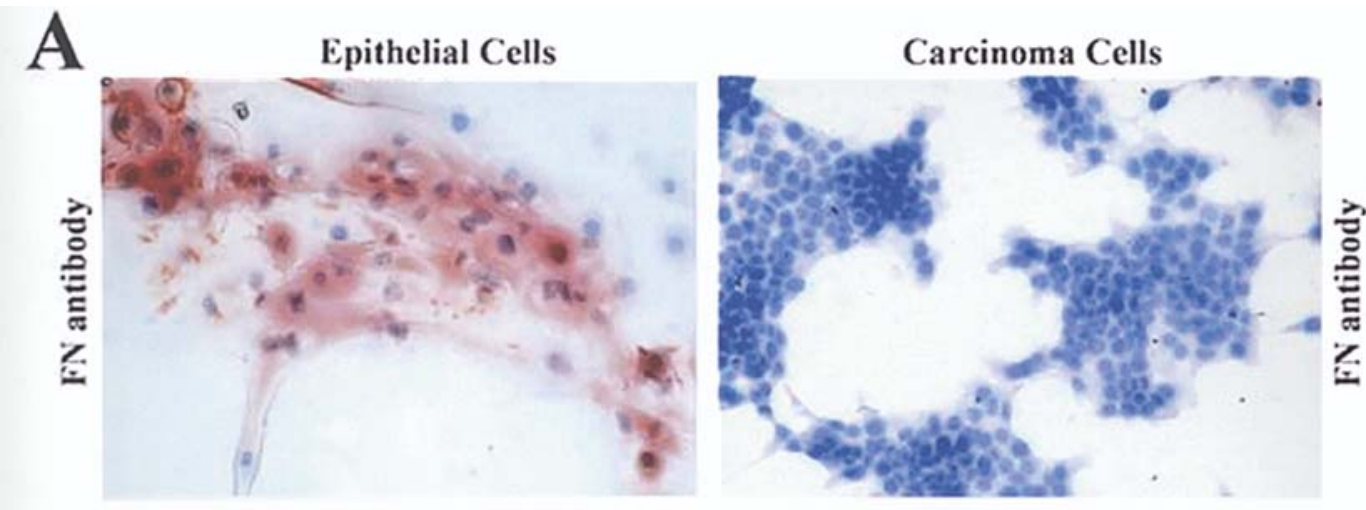

B
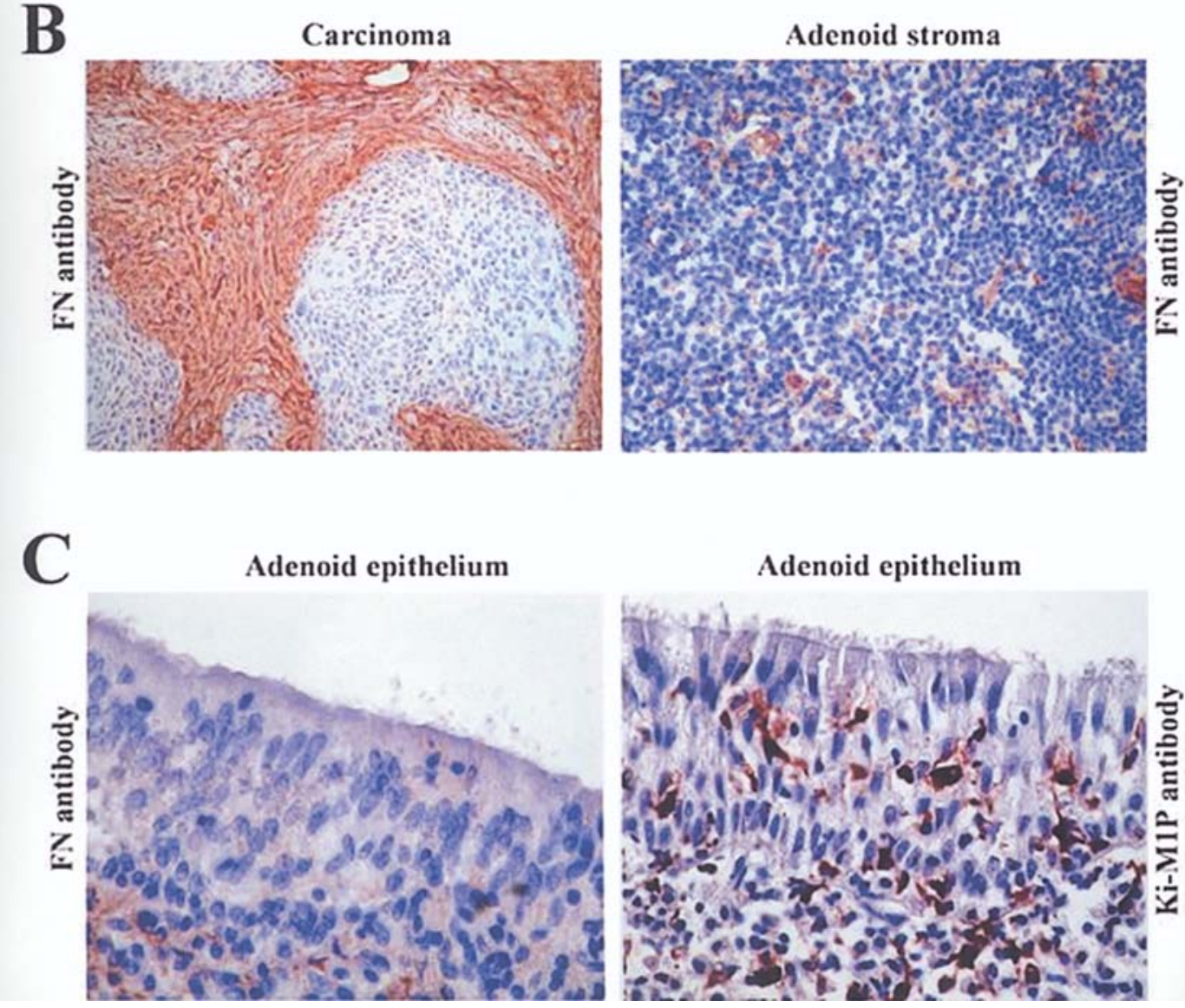

Figure 2. Fibronectin production pattern and leukocyte migration in head and neck carcinomas and adenoids. (A) Immunocytochemistry with fibronectin antibody and hematoxylin staining, magnification x1000. Normal keratinocytes (left panel) show prominent fibronectin expression, whereas UTSCC-19A laryngeal cancer cells (right panel) lack any fibronectin expression. (B) Immunohistochemistry with fibronectin antibody and hematoxylin staining, magnification $\mathrm{x} 200$. The left panel shows a laryngeal carcinoma with absent fibronectin expression in tumor cells, but abundant fibronectin in the tumorassociated stroma. The right panel shows an adenoid sample, demonstrating fibronectin repression throughout the stroma. Fibronectin is visualized only in traces. (C) On the left panel, a x1000 magnification of an adenoid epithelium sample with fibronectin antibody and hematoxylin staining shows almost absent fibronectin production throughout the epithelium. Interestingly, traces of fibronectin can be seen only below the basal membrane, but not within the epithelium. On the left panel, the same adenoid sample is shown with Ki-M1P antibody and hematoxylin staining, magnification x1000. Ciliated epithelium and adjacent submucosa of an adenoid sample are visualized, showing loosening of the tight cellular array as well as migrating T-cells and macrophages throughout the submucosa and epithelium. Several T-cells and macrophages had penetrated the basal membrane and passed through the ciliated epithelium.

oligonucleotide 6 (-220 to -188), 5'-GCG GGC CAT CAG CAT CTC TTT TGT TCG CTG CGA-3'; oligonucleotide 7 (-272 to -221), 5'-AGT TTG ATG ACC GCA AAG GAA ACC GAA AAA AAG TTG TCT TGC CCC AGT CCT G-3'; oligonucleotide 8 (-310 to -273), 5'-TCC CAG CCG CTT CCC ATC CCT TCC CCC ATC CCC TAA AA-3'; oligonucleotide 9 (-355 to -311$), 5$ '-TCT TGC AAC CCC TTC
GCT TCA ACC AAG TCC AGC CAC TCC CTT TCC-3'; oligonucleotide 10 (-390 to -356), 5'-CAC CCC CAA TAA AAA AGA AAA GGG AAG GGG GAG CG-3'; and oligonucleotide 11 (-445 to -391), 5'-GAT TCC CCC CCT CCA CCC CGA AGA GAG GTG ACG CAA TGT CCT CAA ACA CTA CCA C-3'. Negative controls were run without the addition of nucleic proteins. Competitive testing was 
A

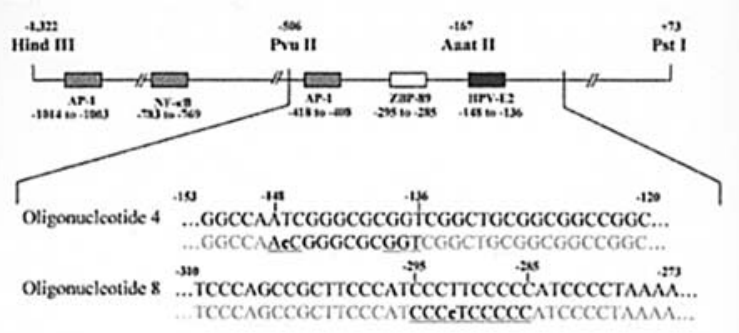

B
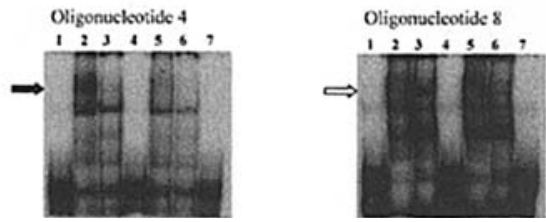

Figure 3. Fibronectin promoter and transcription factors in head and neck cancer cells and benign control. (A) The 5' flanking region of the fibronectin gene coding region, restriction enzyme sites are marked for orientation. (B) Laryngeal carcinoma cells and primary keratinocyte nuclear protein extracts were compared using electrophoretic mobility shift assay, revealing the presence of a shift in the carcinoma cell lines (black arrow) and in the benign keratinocytes (white arrow). Sequence analysis suggested human papilloma virus early protein-2 (HPV E2) and zinc finger transcription factor (ZBP-89) for the carcinoma and the keratinocytes, respectively. Furthermore, binding sites of transcription factors regulated by tumor necrosis factor- $\alpha$ are identified in the fibronectin promoter; i.e. NF- $\kappa \mathrm{B}$, nuclear factor- $\mathrm{\kappa B}$; AP-1, activator protein-1. Lines of the electrophoretic mobility shift assay: 1, oligonucleotide; 2, oligonucleotide and carcinoma nuclear protein extract; 3 , oligonucleotide and keratinocytes nuclear protein extract; 4, negative control (without nuclear proteins); 5, competitive testing, 50-fold excess of non-labeled oligonucleotide and carcinoma nuclear protein extract; 6 , competitive testing, 50-fold excess of non-labeled oligonucleotide and keratinocyte nuclear protein extract; 7, competitive testing of negative control.

achieved using an approximately 50 -fold excess of nonlabelled oligonucleotides. Each protein-DNA complex was analyzed using $5 \%$ nondenaturing polyacrylamide gel at $10^{\circ} \mathrm{C}$ for $1 \mathrm{~h}$. The gels were then dried at $70^{\circ} \mathrm{C}$ for $1 \mathrm{~h}$ and exposed to X-ray films with an intensifying screen at $-80^{\circ} \mathrm{C}$. The sequences of those oligonucleotides that demonstrated a shift were analyzed for potential transcription factor binding sites by the method described by Quandt et al (25).

Cell stimulation. Primary keratinocytes were cultured as described above, and prepared for stimulation with tumor necrosis factor- $\alpha$ (TNF- $\alpha)$, Interleukin-1ß (IL-1ß), and IL-6 (Sigma, Taufkirchen, Germany). All stimulation solutions were freshly prepared in culture medium and pre-warmed to $37^{\circ} \mathrm{C}$ before being placed on the cells, and $5 \times 10^{5}$ cells were seeded into each 6-well tray (Nunc, Roskilde, Denmark). Optimal stimulation was achieved by addition of 50-250 $\mu \mathrm{l}$ stimulation solution to the cell culture medium. The stimulation solution contained either TNF- $\alpha$, IL-1, or IL-6 at a $20-\mathrm{ng} / \mu 1$ concentration. For negative controls, PBS without stimulant was added to the cell culture. After $72 \mathrm{~h}$ of exposure, the medium was decanted, and the cells were washed twice with PBS, fixed in absolute ethanol for $10 \mathrm{~min}$ and subjected to immunocytochemical staining procedures described above. Statistical analysis. Adjusted FN/G3PDH-mRNA quotients as well as FN protein concentrations were analyzed using
SPSS 9.0 (Statistical Package for the Social Sciences, SPSS Inc., Chicago, IL, USA). All data assembled in this study were tested for normal distribution using the KolmogorovSmirnov test. If the data were normally distributed, FN protein concentrations were compared between HNSCC and benign keratinocytes using the paired t-test, and, if otherwise, the Mann-Whitney U-test was applied. FN-mRNA expression was compared between HNSCC and mucosa biopsies using the unpaired t-test. A p-value $<0.05$ was considered significant. In order to confirm significant associations, ANOVA Scheffe's post-hoc test was used.

\section{Results}

FN transcription in HNSCC and adenoids. RNA isolation was confirmed to be sufficient in quantity and quality by agarose gel electrophoresis (Fig. 1). Subsequent Northern hybridization revealed an absence of FN-mRNA in $54 \%$ and moderate reduction $(<0.9 x$ control $)$ in $24 \%$ of the HNSCC samples. Normal FN expression (0.9-1.1x control) was present in $13 \%$ of the HNSCC samples. Interestingly, the FN probe showed an increase of up to $1.5 \mathrm{x}$ of the FN-mRNA expression in $9 \%$ of the HNSCC samples (Table I). All HNSCC samples grouped together $(0.34 \pm 0.47 \mathrm{x}$ control) demonstrated significant FN suppression compared to the benign mucosa control $(\mathrm{p}<0.01)$. Surprisingly, FN expression was strongly repressed throughout all 16 adenoid samples (Fig. 1).

FN translation in HNSCC. To determine transferability of the $\mathrm{FN}$ transcription results to $\mathrm{FN}$ protein synthesis and in order to evaluate causes of increased FN-mRNA in some of the HNSCC samples, FN protein production was assessed by ELISA, immunocytochemistry, and immunohistochemistry. For exemplary ELISA, FN protein concentrations have been measured in five native laryngeal carcinoma samples, derived from the same patient group investigated in this study. Quantitative FN ELISA revealed a 15- to 18-fold repression in laryngeal carcinoma biopsies compared to benign phenotypes (Fig. 1). Immunocytochemistry showed absent FN expression in UTSCC-19A cells compared to benign keratinocytes (Fig. 2A). Immunohistochemistry demonstrated moderate FN repression in the HNSCC cells. Furthermore, prominent FN production was noticed in the tumor-associated stroma surrounding carcinoma cells with FN suppression (Fig. 2B). Tissue inflammation was absent in the HNSCC samples.

Mechanisms of FN suppression in HNSCC. In order to elaborate the mechanisms of the previously described FN suppression in cancer cells, we analyzed the nucleic transcription factors of UTSCC-19A laryngeal carcinoma cells and benign keratinocytes and compared their affinity to eleven FN promoter fragments by means of an electrophoretic mobility shift assay. Our data show two shifts within the first 450 base pairs in the $5^{\prime}$ flanking region of the FN gene, one within the carcinoma cell nucleic protein extracts, and one in the benign control (Fig. 3). A subsequent analysis of the sequence of each $\mathrm{FN}$ promoter fragment that tested positive for a shifting revealed binding sites for human papilloma virus early protein-2 [HPV-E2; binding to 5'-ACC-(N) $)_{6}$-GGT-3'] and the zinc finger transcription factor ZBP-89, with sequence homologies of $87 \%$ and $93 \%$, respectively (Fig. 3). 

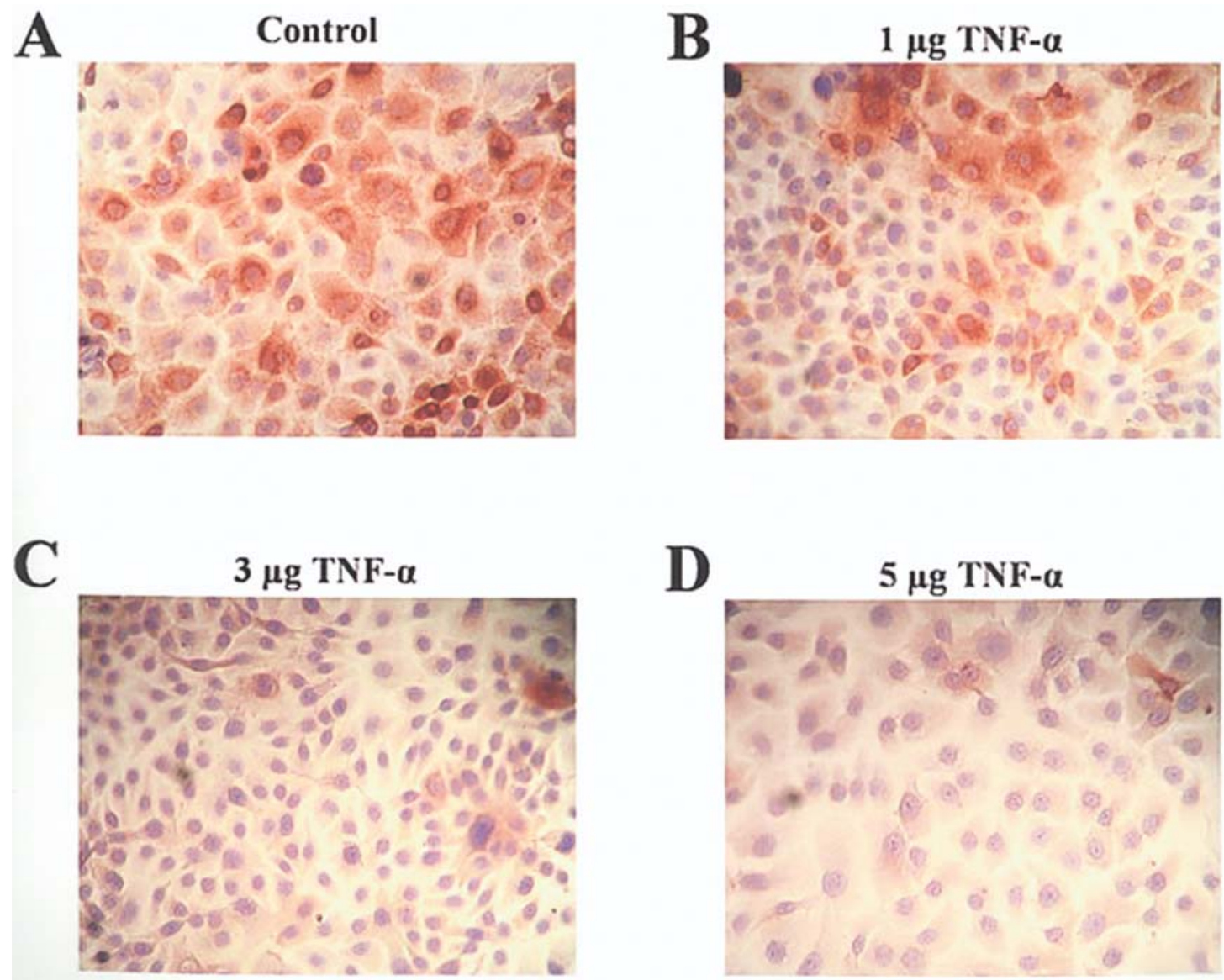

Figure 4. Loss of cellular fibronectin after stimulation of primary keratinocytes with tumor necrosis factor- $\alpha$. Immunocytochemistry with fibronectin antibody and hematoxylin staining, x1000 magnification. (A) Control keratinocytes show prominent fibronectin expression, whereas an increase in the tumor necrosis factor- $\alpha$ concentration in the medium results in gradual fibronectin suppression. (B) Addition of $50 \mu 1$, (C) $150 \mu 1$, and (D) $250 \mu 1$ of a 20 ng tumor necrosis factor- $\alpha / \mu 1$ solution.

FN translation in adenoids. Immunohistochemistry confirmed adenoidal FN-mRNA suppression on the translational level (Fig. 2B and C). More precisely, there were traces of FN throughout the stroma of the adenoid, however, within the epithelium FN was almost undetectable (Fig. 2C). Upon histologic evaluation, the adenoid samples showed hyperplasia and signs of inflammation, and in order to elaborate on a possible connection to concurrent FN suppression, the presence of leukocyte migration needed to be assessed. Therefore, an antibody stain of the adenoid samples demonstrating migrating T-cells and macrophages was required, and the Ki-M1P was applied for its previously described potential to stain both of these leukocyte populations (23). The adenoid samples showed a loose derangement of their normally tightly organized ciliated epithelium (Fig. 2C). Throughout the submucosa as well as the epithelium, abundant Ki-M1P positively stained cells were detected. Many of these cells are shown with signs of cytokinesis, such as cytoplasmatic extensions, suggesting cellular migration (Fig. 2C).

Mechanisms of FN suppression in adenoids. We suspected that FN suppression in the benign epithelial cells of adenoids could be mediated directly from bypassing leukocytes or proinflammatory peptides and chemokines. Therefore, stimulation experiments with TNF- $\alpha$, IL-1ß, and IL- 6 , which are macrophage release products, were conducted in order to assess whether one or more of these peptides would be capable of inducing FN down-regulation and subsequent derangement of cells. Our data show that TNF- $\alpha$ induces FN suppression in a concentration-dependent manner (Fig. 4). Interestingly, IL-1ß, and IL-6 induce FN expression rather than suppressing it (data not shown).

With regard to TNF- $\alpha$ FN suppression, an analysis of the FN gene promoter region sequence using the MatInspector described by Quandt et al revealed binding sites for the transcription factors nuclear factor (NF)- $\mathrm{B}$ and activator protein (AP)-1, which are both activated by TNF- $\alpha$-mediated pathways (Fig. 5) (25). The binding site identified for NF-кB on the FN promoter is from base position -783 to -769 , with a sequence homology of $84 \%$. The AP-1 binding sites are located from -1014 to -1003 and from -418 to -408 with sequence homologies of $95 \%$ and $97 \%$, respectively.

\section{Discussion}

Our data demonstrate prominent FN gene suppression within benign adenoid tissue samples, especially in the epithelium, as well as decreased FN expression in tumor cells in contrast to increased FN expression in the surrounding tumor-associated stroma. The implications of FN suppression and induction within malignant and benign tissues as well as the mechanisms behind these findings are discussed below. 


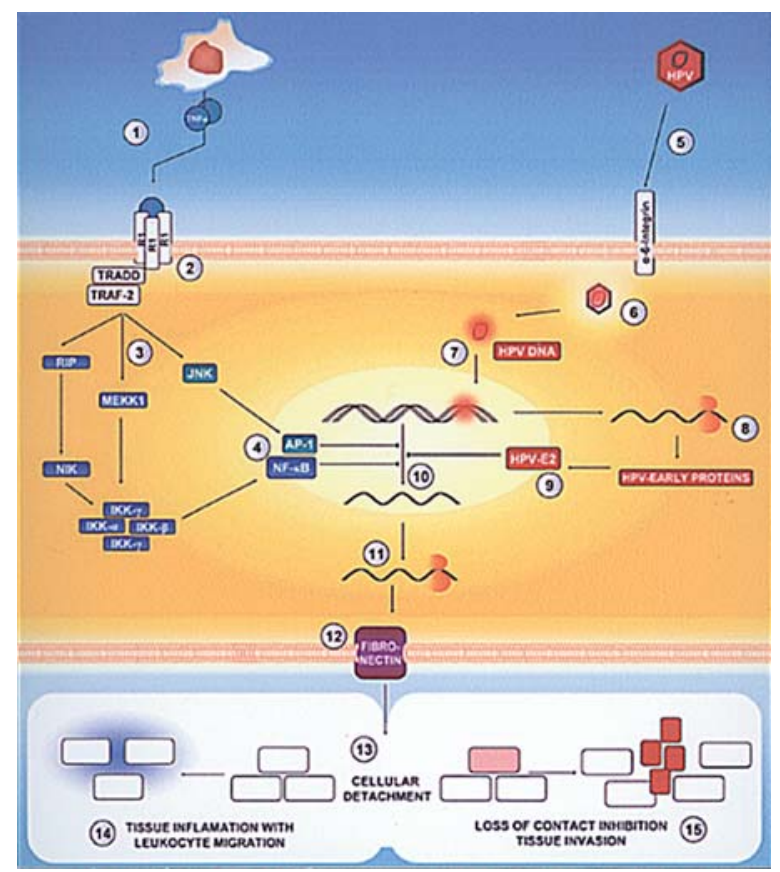

Figure 5. Model of fibronectin suppression in epithelial cells due to benign and malignant etiologies. The left half shows our model for benign fibronectin suppression due to inflammation: (1) Macrophages secrete tumor necrosis factor (TNF)- $\alpha$, which (2) binds to TNF- $\alpha$ receptor-1 (R1). This triggers two different cascades (3) prompting activation of the transcription factors (4) nuclear factor- $\mathrm{B}$ (NF- $\mathrm{B}$ ) and activator protein-1 (AP-1). These bind to the fibronectin promoter and suppress its transcription (10), which leads to a decrease in fibronectin protein synthesis (11) and consequently decreased cellular surface fibronectin (12). This triggers a cellular detachment (13), and supports the passage of leukocytes to follow their chemotactic gradient and induces tissue inflammation (14). The right half shows our model for a pathway of malignant fibronectin suppression. A human papilloma virus (HPV) particle (5) is incorporated into an epithelial cell via endocytosis (6), and the viral DNA is transported into the nucleus. The early transcription of viral DNA to mRNA (7), which undergoes 5' capping and is transported out of the nucleus (8), leads to protein synthesis (8) of HPV early protein-2 (HPV-E2). The HPV-E2 transcription factor is transported back into the nucleus (9) and leads to suppression of the fibronectin gene transcription (10), leading to a reduction of cellular surface protein $(11,12)$, which ultimately results in a loss of contact growth inhibition, and promotes the cell to increased mitosis thus contributing to malignant transformation (15). TRADD, tumor necrosis factor- $\alpha$ receptor associated death domain protein; MADD, mitogen activated kinase activating death domain protein; TRAF2, tumor necrosis factor- $\alpha$ receptor associated factor-2; RIP, receptor interaction protein; NIK, nuclear factor- $\mathrm{B}$ inducing kinase, IKK; inhibitor $\kappa \mathrm{B}$ kinase; JNK, c-Jun N-terminal kinase; MEKK, MAP/ERK-kinase kinase.

FN expression pattern in malignant tumors. FN suppression has been adopted into current models of cancer pathology by numerous authors $(15-18,26)$. Immunohistochemical studies were able to demonstrate strong negative correlations between tumor and normal nodal states comparing FN expression in cervical carcinoma (27) and pulmonary squamous cell carcinoma (28). Regarding HNSCC, FN suppression has been associated with poor prognosis (29) and a loss of cellular differentiation (30). Previous reports indicated that this suppression is mediated on the translational level by revealing a 20 -fold reduction of the FN gene promoter activity (8), and via sequence analysis of the FN promoter region, which indicated several binding sites for potentially inhibiting transcription factors, including the CAAT-binding transcription factor, promoter-specific transcription factor-1, transcription factor-IID, cAMP-responsive element binding protein, and activator protein-2 (31). In addition, our data show HPV-E2 binding to the FN promoter in an HNSCC cell line, which suggests an involvement of HPV in FN suppression. HPV-E2 contains three different domains: the carboxy-end DNA binding domain and the amino-end with transcriptional activation capabilities, which are both separated by a proline rich hinge domain (32). This binds to the partially palindromic sequence 5'-ACC-(N)6-GGT-3' and regulates viral DNA transcription and replication through direct interaction with $\mathrm{G}$ nucleotides in the E2 binding site, through a mechanism that requires E2 dimerization $(33,34)$. The replication cycle of HPV is highly adapted to the host cell maturation from basal cells to fully differentiated epithelial cells (35). Compared to basal cells, the differentiated epithelial cells have a decreased mitosis rate, and the malignant transformation of HPV infections is thought to be an evasion of the host control mechanisms regulating epithelial growth (36). In accordance with these findings, we hypothesize that HPV-E2 could also undermine host growth suppression by inhibiting FN expression in order to optimize viral replication, thus contributing to carcinogenesis.

In contrast to reports suggesting a role of $\mathrm{FN}$ in suppressing tumor growth and invasiveness via contact inhibition, Liu et al postulated a promoting effect of $\mathrm{FN}$ on cancer invasiveness (37). This has been substantiated by findings of increased FN expression in malignant cells of the transitional cell carcinoma (38) and basalioma (39). Furthermore, FN is known to enhance the invasive potential of cancers by promoting malignant and mesenchymal cell interaction (40). In addition, our own data show a partial FN-mRNA increase in some of the HNSCC samples. We offer the following explanations for this finding, supported by our histology findings:

FN suppression in the cancer cells can concur with FN induction in the tumor-associated stroma cells at the same time. Among early signs of malignant transformation, fragmentation of cellular FN is concomitant with an increase in $\mathrm{FN}$ deposition in peritumoral stroma (41). It has been suggested that the outer FN expression results from stimulated fibroblasts rather than tumor cells, and that it enhances tumor growth and cellular movement in the tumor perimeter (42). Experimental procedures that only consider the isolation of whole tissue RNA with an unknown tumor-stroma ratio are therefore unsuitable to determine the association between FN suppression and malignant transformation, unless combined with other investigative strategies able to distinct between the different origins of FN-mRNA. Furthermore, FN suppression and induction are able to concur in the same carcinoma sequentially, i.e. they are both present at different phases of carcinogenesis. Spreading cancer cells can utilize their tumor-associated stroma via cell signaling, assigning it a role comparable to that of a healing wound (43).

These explanations combine both stimulatory and inhibitory effects mediated by $\mathrm{FN}$, thus offering an interpretation of the mixed FN expression profiles of the HNSCC samples as demonstrated in this study. The data obtained from total RNA isolation out of whole tissue samples could not distinguish between tumor and stroma cells. Therefore, our results on FN transcription in HNSCC might be confounded 
by varying quantities of tumor and stroma tissue. Therefore, we applied immunohistochemistry, which supported the model of local alterations in $\mathrm{FN}$ production, i.e. repression in tumor cells opposed to overexpression in the stroma.

Our results also show that FN suppression can be mediated by benign processes rather than malignant transformation alone, which implies additional caution with the interpretation of FN suppression in malignant tumors. Carcinomas are often associated with tissue inflammation, which could offer an additional explanation to FN expression previously described in HNSCC (44). In addition, the presence of leukocytes in the perimeter of a tumor might even suggest a direct contribution to tumor invasiveness and metastasis formation: the dislodgement of intercellular contacts between carcinoma cells secondary to leukocytes mediated by the FN suppression pathway could potentially accelerate cellular migration and cancer spread. The phenomenon of increased tumor invasiveness upon tissue inflammation has been previously reported, especially for pancreas carcinoma, and could also offer a potential molecular target to slow cancer progression $(44,45)$. Leukocyte migration mediated FN suppression. Neither partial nor complete FN suppression has been reported for benign tissues heretofore. The strong suppression of FN expression in adenoids, which were histologically confirmed as benign and without evidence of dysplasia, suggested an involvement of other processes related to the specific properties of tonsillar tissue. Adenoids accommodate numerous Tlymphocytes and macrophages, among other leukocytes, which move in amoeboid fashion throughout the surrounding tissue (46). Ki-M1P antibody staining confirmed abundant T-lymphocytes and macrophages throughout the epithelium, indicating ongoing cytokinesis based on cellular morphology findings. Therefore, the involvement of leukocyte migration in loosening the epithelial array is strongly suggested.

The pattern of leukocyte migration has been studied extensively, and many authors stress the involvement of cytokines such as proinflammatory peptides and the cellular adherence of leukocytes (47-50). Amoeboid movement of leukocytes is ubiquitous in the interior lymphoid three dimensional structure, providing enough room for leukocyte migration. We hypothesize that the FN suppression found in adenoids can be linked to the process of leukocyte migration, which might be conclusive since leukocytes depend on disintegration of junctional complexes in order to be able to move through the epithelium. Our data support this notion since they show epithelial derangement in addition to migrating macrophages and T-cells. We have demonstrated that stimulation of primary keratinocyte cultures with $\mathrm{TNF}-\alpha$, which is a secretion product of macrophages, reduces the expression of $\mathrm{FN}$ on the cellular surface of the keratinocytes in a concentration-dependent manner. We offer the following explanation for this phenomenon (Fig. 5): we have identified binding sites for the transcription factors NF- $\mathrm{NB}$ and AP-1 in the FN promoter. Both NF- $\mathrm{KB}$ and AP-1 are part of the TNF- $\alpha-$ mediated cascade and influence the transcription of various genes (51). Therefore, TNF- $\alpha$ could act on the NF- $\kappa B$ and AP-1 to suppress the FN gene expression, which would finally lead to decreased cellular FN concentrations resulting in epithelial cellular detachment, enabling the macrophages and T-lymphocytes to pass by.
In addition to the data suggesting a necessity of FN down-regulation in order to allow leukocytes to migrate, there are other reports suggesting that high levels of cellular surface FN might impair leukocyte function: fibroblasts of the blood vessel wall have been shown to block monocyte activation via $\mathrm{FN}$ expression thereby preventing damage to the vessel wall during the process of leukodiapedesis (52). It would appear that FN suppression contributes to an effective immune response by enabling leukocytes to reach their target destination, which might be the effect of offending organisms that have penetrated the epithelial layer.

In conclusion, we hypothesize that epithelial FN suppression can concur with benign and malignant processes. We showed that benign FN suppression is associated with tissue inflammation and can be mediated via TNF- $\alpha$ secretion from bypassing migrating leukocytes. Furthermore, our data suggest that the pattern of fibronectin suppression within the tumor structure largely depends on the cancer cell-stroma relation, which could explain previous conflicting reports on its repression or overexpression along with malignant transformation. In addition, our data support an involvement of human papilloma virus as a mechanism of carcinogenesis mediated via a loss of FN gene expression.

\section{Acknowledgements}

We thank Dr George R. Honig, University of Illinois at Chicago, Illinois, and Dr Kandelaria M. Rumilla from the Mayo Clinic, Rochester, Minnesota, for reviewing this manuscript as well as their helpful comments. We gratefully thank Professor Reza Parwaresch from the Department of Hematopathology at the University of Schleswig-Holstein, Campus Kiel, Germany, for providing the Ki-M1P antibodies. Finally, we thank Dr Douglas C. Dean from Washington University, School of Medicine, St. Louis, MI, for providing the FN promoter. This study was supported in part by grants from the IZKF University of Schleswig-Holstein, Campus Kiel, Kiel, Germany

\section{References}

1. Werner $\mathrm{J}$ : The current status of the care for lymph drainage in malignant head-neck tumors. Laryngorhinootologie 76: 643-644, 1997.

2. Moisa I, Mahadevia P and Silver CE: Unusual Tumors of the Larynx. Thieme, New York, NY, pp33-43, 1991.

3. Dolcetti R, Doglioni C, Maestro R, Gasparotto D, Barzan L, Pastore A, Romanelli M and Boiocchi M: p53 over-expression in an early event in the development of human squamous cell carcinoma of the larynx: genetic and prognostic implications. Int J Cancer 52: 178-182, 1992.

4. Fan C, Wong N, Leung SF, To KF, Lo KW, Lee SW, Mok TS, Johnson PJ and Huang DP: Frequent c-myc and Int-2 overrepresentations in nasopharyngeal carcinoma. Hum Pathol 31: $169-178,2000$.

5. Saranath D, Tandle AT, Teni TR, Dedhia PM, Borges AM, Parikh D, Sanghavi V and Mehta AR: High frequency mutations in codons 12 and 61 of Ha-ras oncogene in chewing tobaccorelated human oral carcinoma in India. Br J Cancer 63: 573-578, 1991.

6. Tamas L, Kraxner H, Mechtler L, Repassy G, Ribari O, Hirschberg A, Szentkuti G, Jaray B and Szentirmay Z: Prognostic significance of p53 histochemistry and DNA histogram parameters in head and neck malignancies. Anticancer Res 20: 4031-4038, 2000.

7. Xia W, Lau YK, Zhang HZ, Liu AR, Li L, Kiyokawa N, Clayman GL, Katz RL and Hung MC: Strong correlation between c-erbB-2 overexpression and overall survival of patients with oral squamous cell carcinoma. Clin Cancer Res 3: 3-9, 1997. 
8. Gorogh T, Maune S, Lippert BM, Rudert H, Gottschlich S, Hoffmann M, Meyer J, Heidorn K and Werner JA: Transcriptional repression of the human fibronectin gene in laryngeal squamous cell carcinoma cells. J Cancer Res Clin Oncol 127: 166-172, 2001.

9. Kornblihtt A, Vibe-Pedersen K and Baralle FE: Human fibronectin: cell specific alternative splicing generates polypeptide chains differing in the number of internal repeats. Nucleic Acids Res 12: 5853-5868, 1984

10. Muro A, Chauhan AK, Gajovic S, Iaconcig A, Porro F, Stanta G and Baralle FE: Regulated splicing of the fibronectin EDA exon is essential for proper skin wound healing and normal lifespan. J Cell Biol 162: 149-160, 2003.

11. Glukhova M, Frid MG, Shekhonin BV, Balabanov YV and Koteliansky VE: Expression of fibronectin variants in vascular and visceral smooth muscle cells in development. Dev Biol 141: 193-202, 1990

12. Barnes J, Hastings RR and De la Garza MA: Sequential expression of cellular fibronectin by platelets, macrophages, and mesangial cells in proliferative glomerulonephritis. Am J Pathol 145: 585-597, 1994.

13. Mautner A, Lanza VM and Hynes RO: Restoration of normal morphology, adhesion and cytoskeleton in transformed cells by addition of transformation-sensitive surface protein. Cell 11: 115-126, 1977.

14. Olden K and Yamada KM: Mechanism of the decrease in the major cell surface protein in chick embryo fibroblasts after transformation. Cell 11: 957-969, 1977.

15. Suzuki M, Kuroda C, Oda E, Tsunoda S, Nakamura T, Nakajima T and Oda K: G10BP, an E1A-inducible negative regulator of $\mathrm{Sp} 1$, represses transcription of the rat fibronectin gene. Mol Cell Biol 15: 5423-5433, 1995.

16. Gu H and Oliver N: Transcriptional repression of fibronectin gene expression in v-src transformation. J Cancer Res Clin Oncol 115: 366-374, 1995.

17. Oda E, Shirasuma K, Suzuki M, Nakano K, Nakajima T and Oda K: Cloning and characterization of a GC-box binding protein, G10BP-1, responsible for repression of the rat fibronectin gene. Mol Cell Biol 18: 4772-4782, 1998.

18. Taylor G, Jeffers M, Webb CP, Koo HM, Anver M, Sekiguchi K and Vande-Woude GF: Decreased fibronectin expression in Met/ HGF-mediated tumorigenesis. Oncogene 17: 1179-1183, 1998.

19. Suzuki M, Oda E, Nakayima T, Sekiya S and Oda K: Induction of $\mathrm{Sp} 1$ in differentiating human embryonal carcinoma cells triggers transcription of the fibronectin gene. Mol Cell Biol 18: 3010-3020, 1998.

20. Akiyama S, Olden K and Yamada KM: Fibronectin and integrins in invasion and metastasis. Cancer Metastasis Rev 14: 173-189, 1995.

21. Carey T: Head and neck tumor cell lines. San Diego: Academic pp79-117, 1994.

22. Saffran S, Gorogh T, Lippert BM and Werner JA: Cultivation of human keratinocytes of mucous membranes of the upper aerodigestive tract. Laryngorhinootologie 74: 684-690, 1997.

23. Wacker H, Hansmann ML, Lumbeck H, Radzun HJ and Parwaresch MR: A new pan-macrophage antibody Ki-M1P stains plasmacytoid cells in paraffin sections of lymph nodes. Verh Dtsch Ges Pathol 74: 159-164, 1990

24. Bradford M: A rapid and sensitive method for the quantitation of microgram quantities of protein utilizing the principle of protein-dye binding. Anal Biochem 72: 248-254, 1976.

25. Quandt K, Frech K, Karas H, Wingender E and Werner T: MatInd and MatInspector - New fast and versatile tools for detection of consensus matches in nucleotide sequence data. Nucleic Acids Res 23: 4878-4884, 1995.

26. Stickle N, Chung J, Klco JM, Hill RP, Kaelin WG Jr and Ohh M: pVHL modification by NEDD8 is required for fibronectin matrix assembly and suppression of tumor development. Mol Cell Biol 24: 3251-3261, 2004.

27. Goldberg I, Davidson B, Lerner-Geva L, Gotlieb WH, Ben-Baruch G, Novikov I and Kopolovic J: Expression of extracellular matrix proteins in cervical squamous cell carcinomaa clinicopathological study. J Clin Pathol 51: 781-785, 1998.

28. Hisayoshi T: Prognostic value of Ia-antigen, fibronectin, laminin and type IV collagen in pulmonary squamous cell carcinoma. Nippon Geka Gakkai Zasshi 94: 1209-1217, 1993.

29. Pannizut B, Carlevato MT, Ferro S, Cavalot AL, Gervasio CF, Ricci E, Trusolino L, Marchisio PC and Cortesina G: Adhesion molecules in squamous cell carcinoma of the larynx: possible indication of prognosis. Acta Otorhinol Ital 17: 347-356, 1997.
30. Zidar N, Gale N, Kambic V and Fischinger J: Expression of tenascin and fibronectin in benign epithelial hyperplastic lesions and squamous carcinoma of the larynx. Anticancer Res 21: 451-454, 2001.

31. Kumazaki T and Mitsui Y: Alterations in transcription factorbinding activities to fibronectin promoter during aging of vascular endothelial cells. Mech Ageing Dev 88: 111-124, 1996.

32. McBride A, Romanczuk H and Howley PM: The papillomavirus E2 regulatory proteins. J Biol Chem 266: 18411-18414, 1991.

33. Androphy E, Lowy DR and Schiller JT: Bovine papillomavirus E2 trans-acting gene product binds to specific sites in papillomavirus DNA. Nature 325: 70-73, 1987.

34. Chiang C, Dong G, Broker TR and Chow LT: Control of human papillomavirus type 11 origin of replication by the E2 family of transcription regulatory proteins. J Virol 66: 5224-5231, 1992.

35. Fuchs P and Pfister H: Molecular biology of HPV and mechanisms of keratinocyte transformation. In: Human Papillomavirus Infections in Dermatovenereology. Gross G KG (ed). Boca Raton, CRC Press, pp15-46, 1997.

36. zur Hausen H: Papillomaviruses causing cancer: evasion from host-cell control in early events in carcinogenesis. J Natl Cancer Inst 92: 690-698, 2000.

37. Liu H, Chen B, Zardi L and Ramos DM: Soluble fibronectin promotes migration of oral squamous-cell carcinoma cells. Int $\mathrm{J}$ Cancer 78: 261-267, 1998.

38. Kirkali G, Tuzel E, Guler C, Gezer S and Kirkali Z: Significance of tissue laminin $\mathrm{P}(1)$ elastase and fibronectin levels in transitional cell carcinoma of the bladder. Eur Urol 39: 292-299, 2001.

39. De Rosa G, Barra E, Guarino M, Staibano S, Donofrio V and Boscaino A: Fibronectin, laminin, type IV collagen distribution, and myofibroblastic stromal reaction in agressive and nonagressive basal cell carcinoma. Am J Dermatopathol 16: 258-267, 1994.

40. Shimao Y, Nabeshima K, Inoue T and Koono M: Role of fibroblasts in $\mathrm{HGF} / \mathrm{SF}$-induced cohort migration of human colorectal carcinoma cells: fibroblasts stimulate migration associated with increased fibronectin production via upregulated TGF-beta1. Int J Cancer 82: 449-458, 1999.

41. Labat-Robert J: Fibronectin in malignancy. Semin Cancer Biol 12: 187-195, 2002.

42. David L, Nesland JM, Holm R and Sobrinho-Simoes M: Expression of laminin, collagen IV, bronectin, and type IV collagenase in gastric carcinoma. An immunohistochemical study of 87 patients. Cancer 73: 518-527, 1994.

43. van den Hooff A: Stromal involvement in malignant growth. Adv Cancer Res 50: 159-196, 1988.

44. Kimsey T, Campbell AS, Albo D and Wang TN: Co-localization of macrophage inflammatory protein-3alpha (Mip-3alpha) and its receptor, CCR6, promotes pancreatic cancer cell invasion. Cancer J 10: 374-380, 2005.

45. Khatami M: Developmental phases of inflammation-induced massive lymphoid hyperplasia and extensive changes in epithelium in an experimental model of allergy: implications for a direct link between inflammation and carcinogenesis. Am J Ther 12: 117-126, 2005.

46. Hellings P, Jorissen M and Ceuppens JL: The Waldeyer's ring. Acta Otorhinolaryngol Belg 54: 237-241, 2000

47. Weber C, Alon R, Moser B and Springer TA: Sequential regulation of alpha 4 beta 1 and alpha 5 beta 1 integrin avidity by $\mathrm{CC}$ chemokines in monocytes: implications for transendothelial chemotaxis. J Cell Biol 134: 1063-1073, 1996.

48. Weber C and Springer TA: Interaction of very late antigen-4 with VCAM-1 supports transendothelial chemotaxis of monocytes by facilitating lateral migration. J Immunol 161: 6825-6834, 1998.

49. Springer T and Anderson DC: The importance of the Mac-1, LFA-1 glycoprotein family in monocyte and granulocyte adherence, chemotaxis, and migration into inflammatory sites: insights from an experiment of nature. Ciba Found Symp 118: 120-126, 1986.

50. Suchard S: Interaction of human neutrophils and HL-60 cells with the extracellular matrix. Blood Cells 19: 197-221, 1993.

51. Liz-Grana M and Gomez-Reino Carnota JJ: Tumour necrosis factor. Genetics, cell action mechanism and involvement in inflammation. Allergol Immunol Clin 16: 140-149, 2001

52. Matzner Y, Vlodavsky I, Michaeli RI and Eldor A: Selective inhibition of neutrophil activation by the subendothelial extracellular matrix: possible role in protection of the vessel wall during diapedesis. Exp Cell Res 189: 233-240, 1990. 